\title{
A practical guide to build de-novo assemblies for single tissues of non-model organisms: The example of a Neotropical frog
}

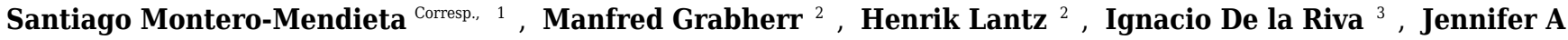 \\ Leonard $^{1}$, Matthew T Webster ${ }^{4}$, Carles Vilà Corresp. 1 \\ ${ }^{1}$ Conservation and Evolutionary Genetics Group, Department of Integrative Ecology, Doñana Biological Station (EBD-CSIC), Consejo Superior de \\ Investigaciones Científicas, Seville, Spain \\ 2 Department of Medical Biochemistry and Microbiology, National Bioinformatics Infrastructure Sweden (BILS), Uppsala Universitet, Uppsala, Sweden \\ 3 Department of Biodiversity and Evolutionary Biology, Museo Nacional de Ciencias Naturales, Consejo Superior de Investigaciones Científicas, Madrid, \\ Spain \\ 4 Department of Medical Biochemistry and Microbiology, Science for Life Laboratory, Uppsala Universitet, Uppsala, Sweden \\ Corresponding Authors: Santiago Montero-Mendieta, Carles Vilà \\ Email address: santiago.montero@ebd.csic.es, carles.vila@ebd.csic.es
}

Whole genome sequencing (WGS) is a very valuable resource to understand the evolutionary history of poorly known species. However, in organisms with large genomes, as most amphibians, WGS is still excessively challenging and transcriptome sequencing (RNA-seq) represents a cost-effective tool to explore genome-wide variability. Non-model organisms do not usually have a reference genome and the transcriptome must be assembled de-novo. We used RNA-seq to obtain the transcriptomic profile for Oreobates cruralis, a poorly known South American direct-developing frog. In total, 550,871 transcripts were assembled, corresponding to 422,999 putative genes. Of those, we identified 23,500, 37,349, 38,120 and 45,885 genes present in the Pfam, EggNOG, KEGG and GO databases, respectively. Interestingly, our results suggested that genes related to immune system and defense mechanisms are abundant in the transcriptome of $O$. cruralis. We also present a pipeline to assist with pre-processing, assembling, evaluating and functionally annotating a de-novo transcriptome from RNA-seq data of non-model organisms. Our pipeline guides the inexperienced user in an intuitive way through all the necessary steps to build de-novo transcriptome assemblies using readily available software and is freely available at: https://github.com/biomendi/TRANSCRIPTOMEASSEMBLY-PIPELINE/wiki 
1 A practical guide to build de-novo assemblies for single tissues of 2 non-model organisms: The example of a Neotropical frog

3

4

5

6

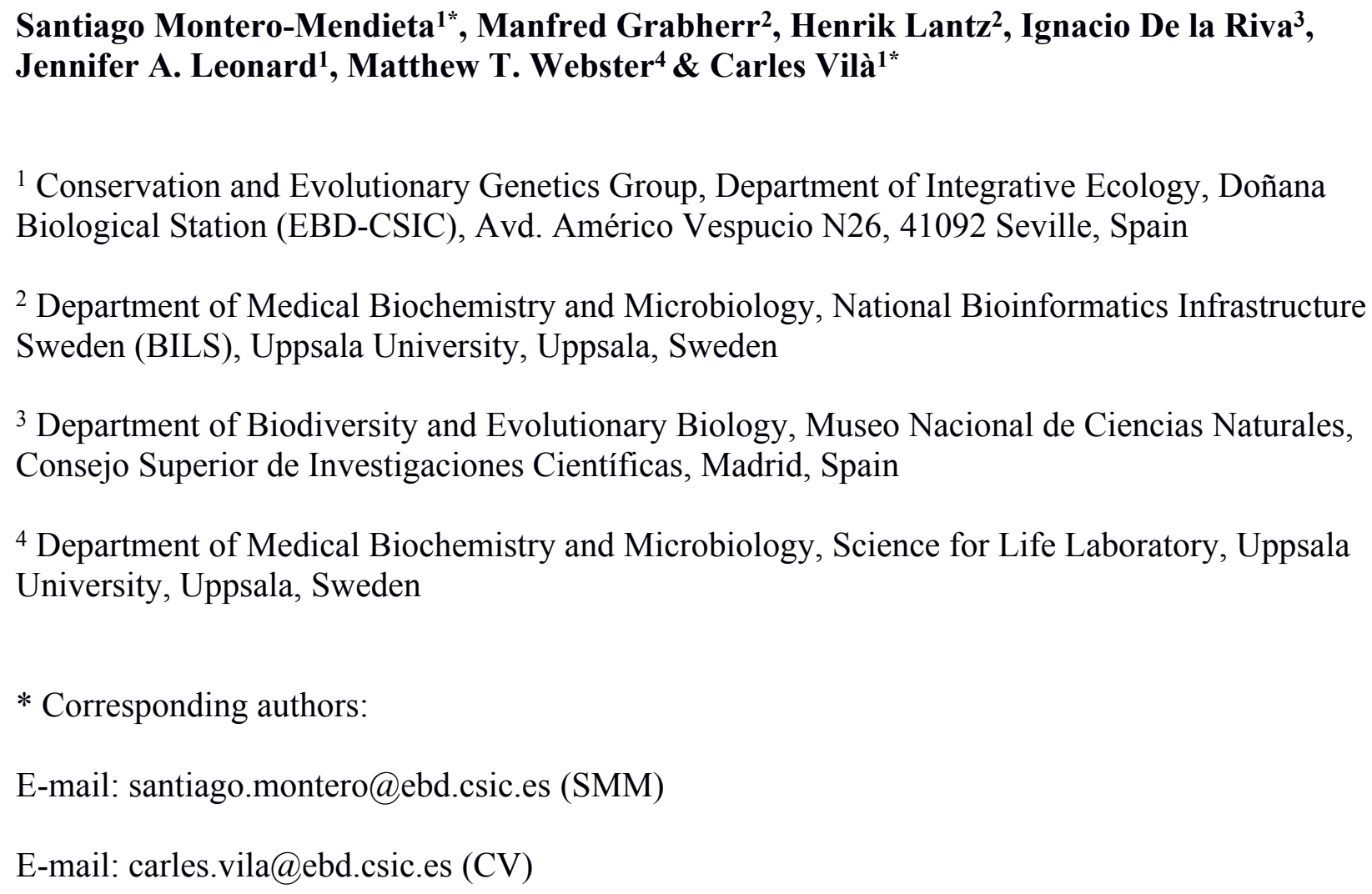


49

50

51

52

53

54

55

56

57

58

59

60

61

62

63

64

65

66

67

68

69

70

71

72

73

74

75

76

77

78

79

80

81

82

83

84

85

86

87

88

89

90

91

92

93

\section{Abstract}

Whole genome sequencing (WGS) is a very valuable resource to understand the evolutionary history of poorly known species. However, in organisms with large genomes, as most amphibians, WGS is still excessively challenging and transcriptome sequencing (RNA-seq) represents a cost-effective tool to explore genome-wide variability. Non-model organisms do not usually have a reference genome and the transcriptome must be assembled de-novo. We used RNA-seq to obtain the transcriptomic profile for Oreobates cruralis, a poorly known South American direct-developing frog. In total, 550,871 transcripts were assembled, corresponding to 422,999 putative genes. Of those, we identified 23,500, 37,349, 38,120 and 45,885 genes present in the Pfam, EggNOG, KEGG and GO databases, respectively. Interestingly, our results suggested that genes related to immune system and defense mechanisms are abundant in the transcriptome of $O$. cruralis. We also present a pipeline to assist with pre-processing, assembling, evaluating and functionally annotating a de-novo transcriptome from RNA-seq data of non-model organisms. Our pipeline guides the inexperienced user in an intuitive way through all the necessary steps to build de-novo transcriptome assemblies using readily available software and is freely available at: https://github.com/biomendi/TRANSCRIPTOME-ASSEMBLYPIPELINE/wiki

\section{Introduction}

The word "genomics" refers to the study of the complete set of genes and gene products in an individual. With the ongoing reduction of costs, this is frequently achieved through the use of high-throughput sequencing technologies (Reuter et al. 2015). The "genomics era" formally started after the Human Genome Project (HGP) was first published in 2001 (Lander et al. 2001). Since then, genomics has drastically changed the way that we understand and study the genetic features of living organisms. Mainly due to novel gene discovery, genomics has proved useful in many fields, such as molecular medicine (Giallourakis et al. 2005), molecular anthropology (Destro-Bisol et al. 2010), social sciences (McBride et al. 2010), evolutionary biology (Wolfe 2006) and biological conservation (Mcmahon et al. 2014), among others. Nowadays, a main use of genomics is to profile genomes, transcriptomes, proteomes, and metabolomes (Schuster 2008). Genomics has also proved highly informative in elucidating evolutionary history of species and, for example, has enabled finding genes that could explain the variation in beak size within and among species of Darwin's finches, in addition to providing new insights into the evolutionary history of these birds (Lamichhaney et al. 2015, 2016).

At the time of writing this article (January 2017), 8951 genomes had been completely sequenced according to the Genomes OnLine Database (GOLD) (https://gold.jgi.doe.gov) (Mukherjee et al. 2017). These genomes include mainly unicellular organisms (4,958 bacteria; 240 archaea) and viruses $(3,473)$ due to their small genome size. Eukaryote organisms usually have larger genomes and the sequencing effort to fully sequence them is much larger. Only 280 eukaryote genomes have been completed, most of them belonging to model organisms (i.e. species that have been widely studied because of particular experimental advantages or biomedical interest). However, the difficulties associated with the assembly of large genomes have resulted in very few of these being fully sequenced. Among terrestrial vertebrates, amphibians have the largest 
94 genome sizes. The average genome size of frogs is 5.0 gigabases $(\mathrm{Gb})$, while the fire salamander 95 (Salamandra salamandra) genome averages $34.5 \mathrm{~Gb}$ (Gregory et al. 2007). For this reason, few 96 genomics studies on amphibians have been carried out so far. To date, only the genome of three 97 frogs of reduced genome size, Xenopus tropicalis (1.5Gb; Hellsten et al. 2010), Xenopus laevis 98 (2.7Gb; Session et al. 2016) and Nanorana parkeri (2.3Gb; Sun et al. 2015), have been 99 sequenced and published, in contrast to the larger number of genomes of reptiles (10), birds (53) 100 and mammals (43). Due to the difficulties to obtain reference genome sequences for species with 101 large genome sizes, reduced representation approaches are a cost-effective way to obtain 102 information on genome-wide variability. For non-model organisms in which whole genome 103 sequencing (WGS) is not feasible, transcriptome (e.g. Geraldes et al. 2011; De Wit et al. 2015) 104 or exome (Lamichhaney et al. 2012) sequencing are commonly used as a reduced representation 105 of the genome.

106

107

In amphibians, 24 transcriptomes from 19 species are currently available in the Transcriptome Shotgun Assemblies (TSA) database (https://www.ncbi.nlm.nih.gov/genbank/tsa/, January 2017), highlighting the importance of RNA sequencing (RNA-seq) for genomic studies in this group. RNA-seq is more affordable than whole genome sequencing and has rapidly become the preferred method for cataloguing and quantifying the complete set of transcripts or messenger RNA for a specific tissue, developmental stage or physiological condition (Wang et al. 2009). Nowadays, RNA-seq has a wide variety of uses but the core analyses include transcriptome profiling, differential gene expression and functional profiling (Conesa et al. 2016). As transcriptome assembly becomes more common for non-model and poorly known organisms, we expect it will become a more popular tool also in phylogenomics as well as in demographic and population structure inference. However, what kind of RNA-seq data analysis is to be performed depends on the species of interest and the research goals. For model organisms and their close relatives, RNA-seq data is analyzed by mapping reads to a reference genome. By contrast, most non-model organisms do not have a reference genome from a sufficiently closely related species, and the transcriptome must be assembled de-novo (Martin \& Wang 2011). Many bioinformatics tools to build a de-novo transcriptome are now available, yet contrasting opinions about the steps to follow may be disorienting. Some extremely simple pipelines have been developed to automatize the process (e.g. TRUFA; Kornobis et al. 2015), but this may limit the flexibility of the different pieces of software that have been integrated.

Here, we present the transcriptome profile for Oreobates cruralis, a direct-developing frog species from the Amazonian regions of Bolivia and Peru. To date, this is the first transcriptome available for a South American amphibian. We also present a simple pipeline for pre-processing, building and functionally annotating a de-novo transcriptome from RNA-seq data of non-model organisms using available software.

134

135

136

137

\section{Methods}

\section{Study model and sample collection}

The genus Oreobates Jiménez de la Espada, 1872 (Anura: Craugastoridae) is a poorly 139 studied clade of New World direct-developing frogs (Terrarana) distributed from the lower slopes of the eastern Andes into the upper Amazon basin, encompassing from southern Colombia 
140 and western and central Brazil up to northern Argentina. More than half of the 24 identified 141 species have been described in the last decade and the species diversity in this genus is likely to 142 be underestimated (Köhler \& Padial 2016). One of these species, O. cruralis (Boulenger, 1902) 143 occurs in a wide range of elevations and habitats across Bolivia and Peru. Its distribution 144 includes lowland Amazonian rainforests (approximate altitudinal range, from 100 to 600 meters above sea level, m.a.s.1.), Yungas-montane Amazonian rainforests (600-2500 m.a.s.1.), and interAndean dry valleys (1300-3000 m.a.s.1.) (De la Riva et al. 2000). However, little is known about its ecology and evolutionary history.

For this study we used tissue samples from a single individual of $O$. cruralis, sampled in Bolivia (Villa Tunari, Cochabamba, Bolivia; 345 m.a.s.1.; 16 59'01.4"S 65²4'30.16"W) on November

151

152

153

154

155

156

157

158

159

160

161

162

163

164

165

166

167

168

169

170

171

172

173

174

175

176

177

178

179

180

181

182

183

184

185 28th, 2013 and deposited at the tissue collection of the Museo Nacional de Ciencias Naturales (MNCN-CSIC) in Madrid, Spain (MNCN/ADN:65263; Colección Boliviana de Fauna, CBF 7268) for which some tissue samples were available. Unfortunately, the specimen was unsexed. Samples of five tissues (intestine, liver, spleen, heart and skin) were isolated and preserved in Nucleic Acid Preservation (NAP) buffer (Camacho-Sánchez et al. 2013) at the time of sampling and were later kept at $-80^{\circ} \mathrm{C}$. Unfortunately, no other tissues were preserved under the same conditions.

\section{Ethics statement}

Field surveys that led to sampling the studied specimen were approved by the Dirección General de la Biodiversidad, Ministerio de Medio Ambiente y Agua, La Paz, Bolivia (Approval number: MMAyA-VMA-DGBAP $\mathrm{N}^{\mathrm{0}}$ 1592/12), and were supported and approved by the Spanish Government (Ministerio de Economía y Competitividad, Project numbers: CGL2011-30393 and CGL2013-47547-P, awarded to IDIR).

\section{Transcriptome sequencing}

We extracted whole RNA for each tissue using the RNeasy Protect Mini Kit (Qiagen). RNA quality was evaluated with RNA ScreenTape on TapeStation by Agilent. Due to poor RNA quality, two tissues were discarded (skin and heart), thus only RNA extracts from intestine, liver and spleen were used (RIN, RNA integrity number, scores of 6.2, 7.3 and 7.1, respectively). Sequencing libraries were prepared and sequenced by the SNP\&SEQ Technology Platform (Uppsala University) from $1 \mu \mathrm{g}$ total RNA using the TruSeq stranded mRNA library preparation kit (Illumina Inc.) and including poly-A selection. The library preparation was performed according to the manufacturers' protocol. The quality of the libraries was evaluated using the Agilent Technologies TapeStation and a DNA 1000-kit Screen Tape. The adapter-ligated fragments were quantified by qPCR using the Library quantification kit for Illumina (KAPA Biosystems) on a StepOnePlus instrument (Applied Biosystems/Life technologies) prior to cluster generation and sequencing. A $14 \mathrm{pM}$ solution of RNA was subjected to cluster generation and paired-end sequencing with 125 bp (base pair) read length on a HiSeq2500 instrument (Illumina Inc.) using the $\mathrm{v} 4$ chemistry according to the manufacturer's protocols.

\section{RNA-seq data analysis}


186

187

188

189

190

191

192

193

194

195

196

197

198

199

200

201

202

203

204

205

206

207

208

209

210

211

212

213

214

215

216

217

218

219

220

221

222

223

224

225

226

227

228

229

230

231

The overall pipeline is summarized in Figure 1 and our practical guide is available at: https://github.com/biomendi/TRANSCRIPTOME-ASSEMBLY-PIPELINE/wiki. Briefly, the first step after obtaining the raw sequence data in FASTQ format was to perform a preliminary quality control analysis with (http://www.bioinformatics.babraham.ac.uk/projects/fastqc/). FastQC delivers quality metrics that are useful to identify if the data requires initial pre-processing before the transcriptome assembly. The pre-processing stage included three steps: first, removal of possible ribosomal RNA (rRNA) contamination; second, trimming low quality bases and PCR adapters; third, normalization to remove large excess of reads corresponding to moderately and highly expressed transcripts. Pre-processing is not always needed but it is highly recommendable to improve assembly quality. Once the data was pre-processed, a quality control was performed again and then, clean normalized reads were de-novo assembled in absence of a reference genome. Subsequent analyses depend on the study goals. In our case, transcripts were functionally annotated using various databases to obtain a transcriptome profile. All steps are described in further detail in the following paragraphs.

We filtered raw FASTQ reads using SORTMERNA-v2.1 (Kopylova et al. 2012) against 8 default rRNA databases (SILVA 16S bacteria, SILVA 16S archaea, SILVA 18S eukarya, SILVA 23S bacteria, SILVA 23s archaea, SILVA 28S eukarya, Rfam 5S archaea/bacteria, Rfam 5.8S eukarya) to remove rRNA. Then, we used TRIMMOMATIC-v0.32 (Bolger et al. 2014) to trim adaptors and sequences with Phred quality score $<20$. We normalized cleaned data of each tissue using the in-silico normalization utility included in the TRINITY-2.2.0 package (Grabherr et al. 2011). Normalization is useful for large RNA-seq data sets ( $>300$ million paired-end reads) because it will remove over-expressed transcripts, thus lowering computing memory consumption and speeding up the assembly process (Haas et al. 2013). We merged the resulting data for the three tissues into a single dataset and normalized again to remove redundant sequences that could have been obtained from several tissues prior to assembly. We used TRINITY (Grabherr et al. 2011) to de-novo assemble normalized reads into contigs. This resulted in a large number of transcripts, much higher than the expected number of genes, likely because of alternative splicing. To avoid redundant transcripts, we kept the longest isoform for each "gene" identified by TRINITY (unigene) using the "get_longest_isoform_seq_per_trinity_gene.pl" utility in TRINITY. Thus, each unigene represented a collection of expressed sequences (i.e. transcripts) that apparently came from the same transcription locus, representing a putative gene. This set of unigenes was kept for downstream analyses.

We evaluated the quality of the assembly and the transcript contiguity in terms of read representation by mapping normalized reads back to the set of unigenes using BOWTIE-1.1.2 (Langmead et al. 2009). We assessed the assembly completeness in terms of gene content using BUSCO-v1 (Simao et al. 2015) by searching the unigenes for the presence or absence of conserved orthologs in the tetrapoda-odb9 database (http://busco.ezlab.org/datasets/tetrapoda_odb9.tar.gz) that represents a collection of 3,950 single-copy tetrapoda orthologs. We also mapped with E-value $\leq 1 \mathrm{E}-20$ the unigenes to the SwissProt database (ftp://ftp.ebi.ac.uk/pub/databases/uniprot/) and to the Western clawed frog (Xenopus tropicalis)

proteome (http://ftp.ensembl.org/pub/release81/fasta/xenopus_tropicalis/pep/Xenopus_tropicalis.JGI_4.2.p 
232 ep.all.fa.gz) using BLASTX (searches within a protein database using a translated nucleotide 233 query) included in the NCBI-BLAST-2.4.0+ package (Altschul et al. 1990). The SwissProt is a 234 curated protein sequence database aimed to provide a high level of annotation (e.g. the 235 description of the function of a protein), a minimal level of redundancy and high level of 236 integration with other databases (Bairoch \& Apweiler, 200). There is no perfect E-value cut-off 237 in BLAST, but the smaller the most reliable the match. We used orthologous proteins found in 238 SwissProt and $X$. tropicalis to assess completeness as described by Haas et al. (2013).

239

240

We predicted protein-coding regions in the unigenes based on the most likely longest-ORF using TransDecoder-v3 (Haas et al. 2013). In order to annotate the sequences we compared them to public databases compiled for different purposes. We searched homolog sequences for the predicted proteins using BLASTP (search protein database using a protein query) with E-value $\leq$ 1E-5 to the SwissProt database. We also used BLASTX with E-value $\leq 1 \mathrm{E}-5$ to search homolog sequences for the unigenes compared to the SwissProt database. In both cases, BLASTP and BLASTX, we only kept top-hit matches. We used BLAST2GO (Conesa et al. 2005) to detect the species distribution of the top BLASTX results within the SwissProt database. We identified protein domains using HMMER-3.1b2 (Finn et al. 2011) to the Pfam-A database (ftp://ftp.ebi.ac.uk/pub/databases/Pfam/). Homologous proteins found in the SwissProt database were used to retrieve functional annotation comments from the GO (Gene Ontology; Ashburner et al. 2000), EggNOG (Evolutionary Genealogy of Genes: Non-supervised Orthologous Groups; Powell et al. 2012) and KEGG (Kyoto Encyclopedia of Genes and Genomes; Kanehisa et al. 2012) databases using TRINOTATE-v.3 (https://trinotate.github.io). The software also searched

254 GO terms in Pfam results and in the combined results of homology search via SwissProt and Pfam. At the time of conducting this study, TRINOTATE was built around specific releases of SwissProt and Pfam databases available at https://data.broadinstitute.org/Trinity/Trinotate_v3_RESOURCES/). We used BLAST2GO to categorize the annotated GO terms in the combined results of SwissProt and Pfam searches. EggNOG annotations were filtered to keep COGs (Clusters of Orthologous Groups) and those were categorized using the current version of the COG database (ftp://ftp.ncbi.nih.gov/pub/COG/COG2014/data). KEGG annotations were filtered to keep KOs (KEGG orthology) and those were categorized using the tool "Reconstruct Pathway" (http://www.kegg.jp/kegg/tool/map_pathway.html).

\section{Data availability}

Raw RNA-seq data in FASTQ format has been deposited at the NCBI Sequence Read Archive database (SRA) under the accession SRP106442. The transcriptome assembly in FASTA format has been deposited at DDBJ/EMBL/GenBank under the accession GFNJ00000000. The quality of the assembly was examined through the NCBI contamination screen. The screen found 5 sequences to exclude, 105 sequences with locations to mask/trim and 6 potentially duplicated sequences (with 3 distinct checksums). As a result, the uploaded information contained 422,970 sequences $(188,369,677 \mathrm{bp})$ rather than the initial 422,999 sequences $(188,399,293 \mathrm{bp})$. All the data is available at NCBI BioProject under the accession PRJNA384528. 
Figure 1: Overall pipeline for the annotation of RNA-seq data. Boxes with curved sides represent sequence datasets. Red boxes

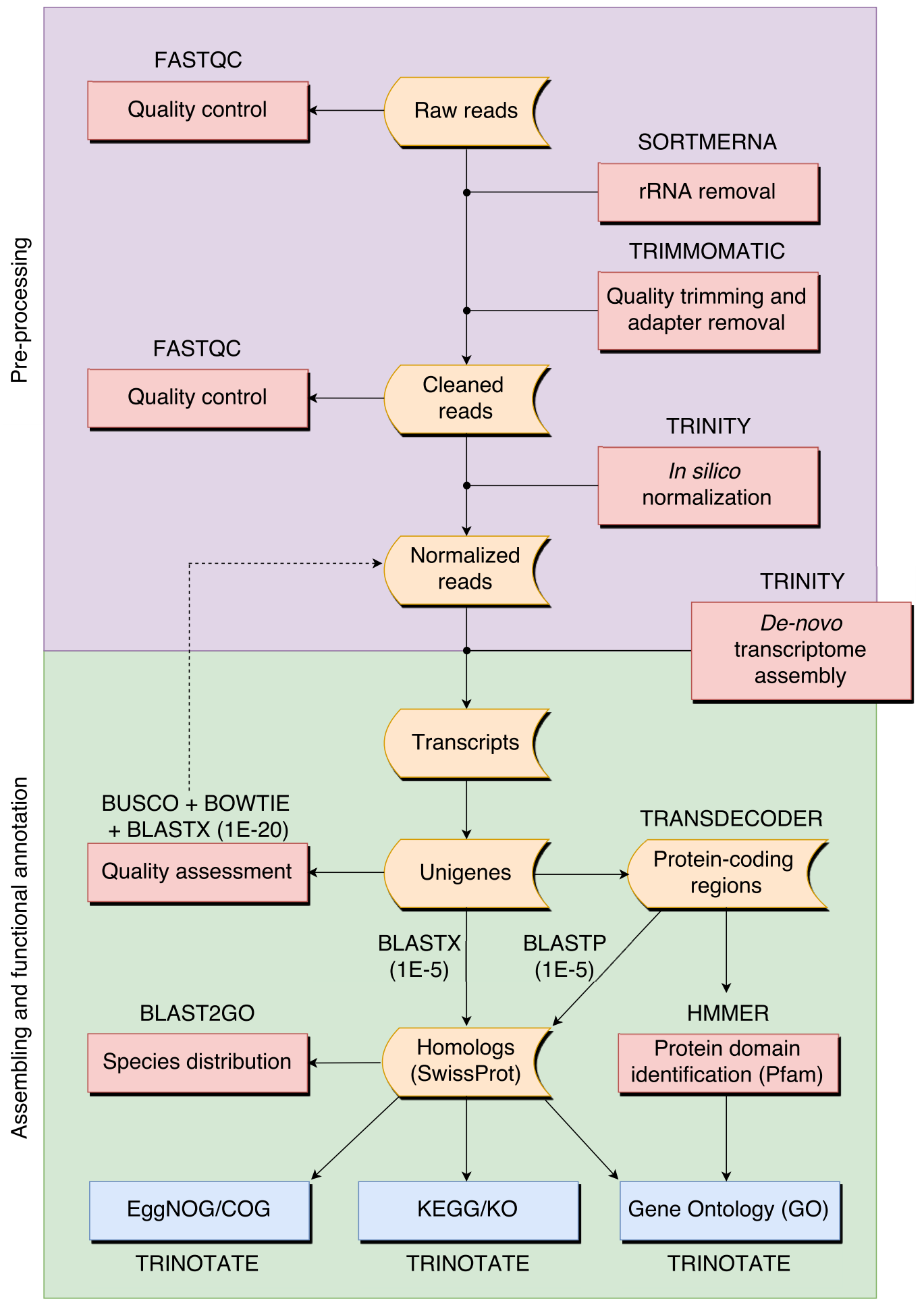




\section{RNA sequencing and transcriptome assembly}

A summary of the RNA-seq data and transcriptome assembly is presented in Table 1. Illumina RNA sequencing for three tissues of $O$. cruralis in an Illumina HiSeq2500 instrument produced a total of almost $523 \times 10^{6}$ raw reads (intestine: $194 \times 10^{6}$; liver: $189 \times 10^{6}$; spleen: 140 $\left.\mathrm{x} 10^{6}\right)$. Of those, $81.47 \%$ were kept after the pre-processing stage $\left(426 \times 10^{6}\right)$. The number of reads was further reduced to $6.97 \%$ after in silico normalization prior to assembly $\left(36 \mathrm{x} 10^{6}\right)$. This highlights the importance of normalization to remove over-expressed transcripts in RNA-seq data. A total of 550,871 transcripts were obtained after de-novo transcriptome assembly. This large number of transcripts is not too surprising, both in terms of RNA-seq assembly as well as given the species and its likely large genome (see genome size for closely related genera at: http://www.genomesize.com/). First, transcriptome assemblies often include incompletely spliced introns, orphaned UTRs, read through off of the 3 ' ends, spuriously transcribed regions, active transposable elements, etc., so the number of assembled transcripts typically exceeds the expected number of protein coding genes by an order of magnitude. Second, large genomes tend to have large transcriptomes. In the axolotl (Ambystoma mexicanum) the transcriptome assembly had $\sim 1.5 \times 10^{6}$ transcripts that clustered into $\sim 1.3 \times 10^{6}$ putative genes (unigenes), and of those, 110,000 mapped to 30,000 SwissProt genes (Bryant et al. 2017). It is possible that these large genomes include a large number of repetitive sequences transcribed, which makes assembly more difficult and results in more fragmentation, especially when using diginorm (as in TRINITY) or any other in silico normalization. In $O$. cruralis the 550,871 transcripts clustered into 422,999 unigenes. This difference in number is likely because of alternatively spliced isoforms derived from paralogous genes (Wang et al. 2014). However, this will need to be confirmed with new amphibian genomes as they become available. Unigenes in the transcriptome of $O$. cruralis had an average GC content of $45.39 \%$, which is very similar to other amphibians, such as the axolotl (A. mexicanum 45.56\%; Hall et al. 2016), the green toad (Bufotes viridis 46.83\%; Gerchen et al. 2016) or the common frog (Rana temporaria 44\%; Price et al. 2015). The size of the unigenes in $O$. cruralis ranged from 201 to $16,804 \mathrm{bp}$ with a mean length of $445 \mathrm{bp}$ and a N50 length of $467 \mathrm{bp}$ (Table 1; Figure 2). The N50 value indicates that half of the transcriptome unigenes were at least $467 \mathrm{bp}$ in length. The N50 length has been proposed as an estimator of genome assembly contiguity, since better assemblies will result in longer contigs (Li et al. 2014; Simpson 2014). However, in transcriptome data this measure can be highly misleading because it does not assess assembly completeness in terms of read representation or gene content (Simao et al. 2015). 
Table 1: Summary of the transcriptome data assembly for Oreobates cruralis.

\begin{tabular}{ll}
\hline \multicolumn{2}{c}{ PRIOR TO DE-NOVO TRANSCRIPTOME ASSEMBLY } \\
\hline Length of raw reads (bp) & 125 \\
\hline Total number of raw reads & $522,877,358$ \\
\hline Total number of clean reads & $426,003,462$ \\
\hline \multicolumn{1}{c}{ AFtal number of normalized reads } & $36,428,858$ \\
\hline \multicolumn{1}{c}{ AFE-NOVO TRANSCRIPTOME ASSEMBLY } \\
\hline Total number of all transcripts / unigenes & 550,871 / 422,999 \\
\hline GC-content of all transcripts / unigenes (\%) & 45.88 / 45.39 \\
\hline Total length of all transcripts / unigenes (bp) & $299,133,111 / 188,399,293$ \\
\hline N50 length of all transcripts / unigenes (bp) & $731 / 467$ \\
\hline Mean length of all transcripts / unigenes (bp) & $543 / 445$ \\
\hline Median length of all transcripts / unigenes (bp) & $309 / 290$ \\
\hline
\end{tabular}

Figure 2: Length distribution of unigenes from Oreobates cruralis.

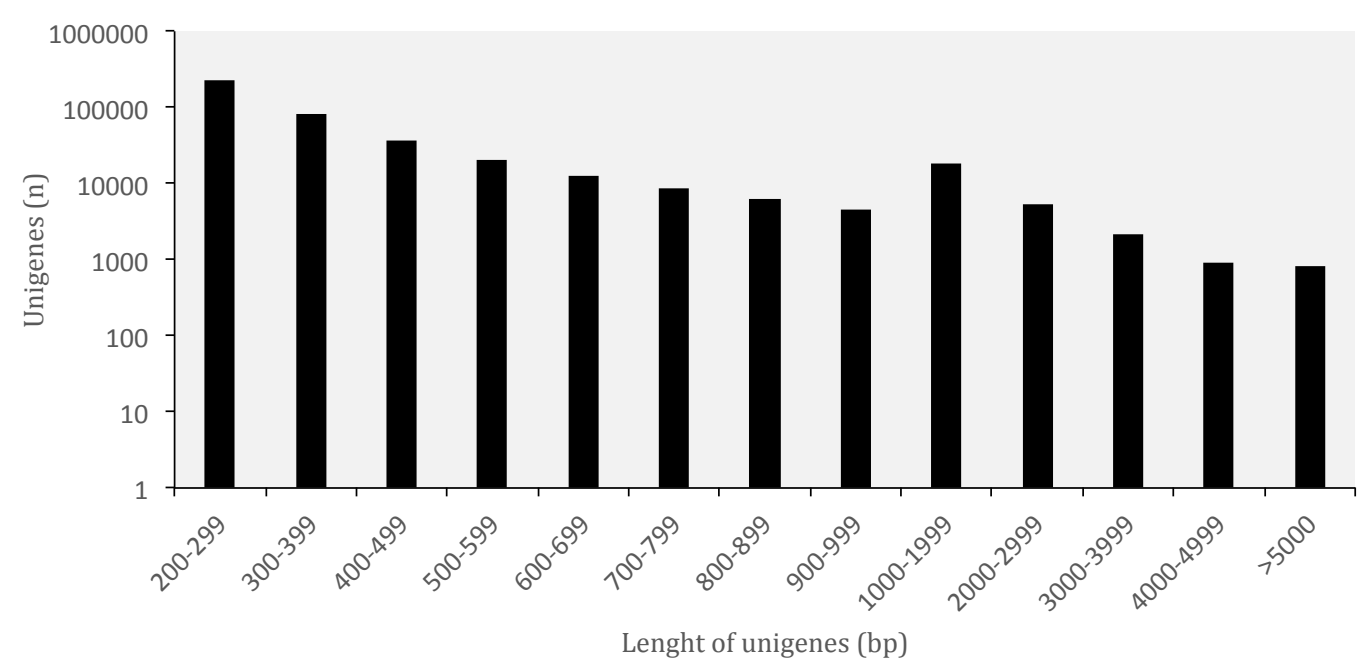

\section{Transcriptome quality assessment}

The set of assembled unigenes might not always perfectly correspond to all properly paired reads, as some unigenes might be built from just a portion of reads coming from the same transcription locus. When we evaluated assembly quality in terms of read representation, we found a high rate of reads that mapped back to unigenes $(75.40 \%)$, thus confirming the presence of most of the initial reads in our final set of unigenes. When we evaluated the assembly completeness in terms of gene content, we found 2,830 complete orthologous genes $(71.65 \%)$ out of the 3,950 genes available in the tetrapoda database (complete BUSCO hits). Of those, 
2,501 were single-copy genes and 329 were duplicated genes. Only $462(11.70 \%)$ of the genes in the database appeared fragmented and $658(16.65 \%)$ were missing. We also obtained a high number of orthologous proteins in both the SwissProt and the $X$. tropicalis databases that fully matched ( $100 \%$ alignment coverage) or nearly fully corresponded ( $>80 \%$ alignment coverage) to unigenes in $O$. cruralis (Figure 3). Altogether, the high number of complete (or nearly complete) orthologous matches across the different databases provides a valuable validation of the depth and completeness of the assembly process.

Figure 3: Distribution of BLASTX alignment coverage for $O$. cruralis unigenes against SwissProt and Xenopus databases. A high number of orthologous proteins in the databases fully or nearly fully corresponded ( $>80 \%$ coverage) to unigenes in $O$. cruralis

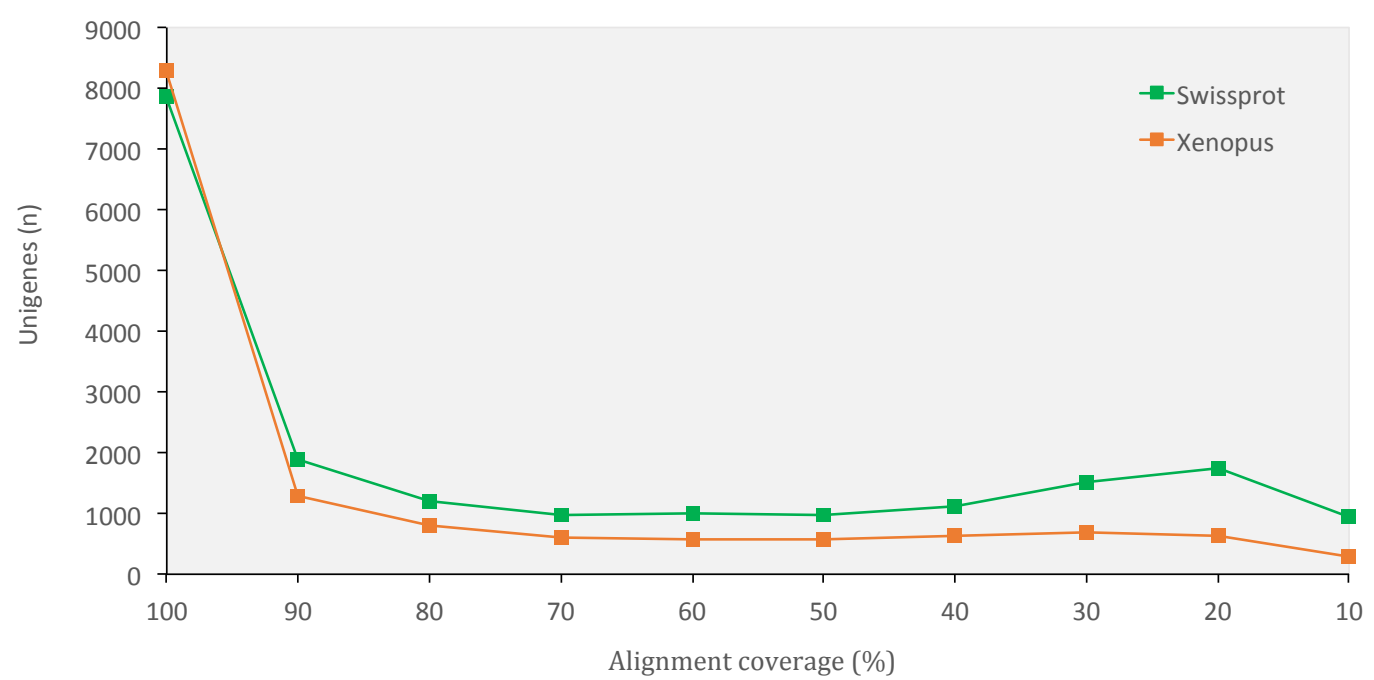

\section{Functional annotation of unigenes}

Gene annotation consists of adding relevant biological information to coding regions of the genome and it was arguably the most relevant section of our pipeline, since it allowed us to describe and classify the content of the $O$. cruralis transcriptome. Functional annotation was based on BLAST searches to find homologous proteins within a reference database (e.g. SwissProt) and the collection of biological information from various sources (e.g. GO, KEGG, EggNOG or Pfam). We predicted a total of 45,466 protein-coding genes within the 422,999 unigenes using TansDecoder. After homology search using BLASTP, we found that 26,418 protein-coding genes in $O$. cruralis mapped to proteins in the SwissProt database. Search using BLASTX revealed a total of 54,425 unigenes that mapped to proteins in the $X$. tropicalis proteome and 47,349 unigenes that mapped to proteins in the SwissProt database. The relative low number of homologous proteins shared between $O$. cruralis and X. tropicalis, just $12.8 \%$ of all unigenes identified in $O$. cruralis, is likely consequence of the very ancient divergence time between both species (estimated to be around 204 million years ago; http://www.timetree.org/). This ancient divergence implies long time for the accumulation of mutations. However, the observation of a number of matches $(54,425)$ that is larger than the total number of proteins in $X$. tropicalis $(22,718)$ may suggest that many of them might be duplicates or unresolved splice variants among the unigenes of $O$. cruralis. The version of the SwissProt database used included 
382

383

384

385

386

387

388

389

390

391

392

393

394

395

396

397

\section{8}

399

400

401

402

403

404

405

406

407

408

409

410

411

412

413

a selection of 553,231 protein sequences from 13,379 species, and the top-hit species distribution showed that $32 \%(13,099)$ of the $O$. cruralis unigenes were homologs to human (Homo sapiens) proteins and 19\% (7661) to house mouse (Mus musculus) proteins (Figure 4). The larger number of hits to mammals than to other amphibians is likely due to the uneven distribution of species in the SwissProt database, in which the top twenty species accumulate $21.5 \%$ of the entries. Still, amphibian species were highly represented in the assembly with $10 \%$ (3909) of the O. cruralis unigenes having a highest match to X. laevis and 5\% (1893) to X. tropicalis proteins. When we retrieved the functional comments for the homologous proteins found in the SwissProt database, the number of annotated unigenes varied depending on the source that was used: a total of $45,885,38,120,37,349$ and 23,500 unigenes were annotated for GO, KEGG, EggNOG and Pfam databases, respectively.

Figure 4: Top-hit species distribution for unigenes from the transcriptome of $O$. cruralis in the SwissProt database.

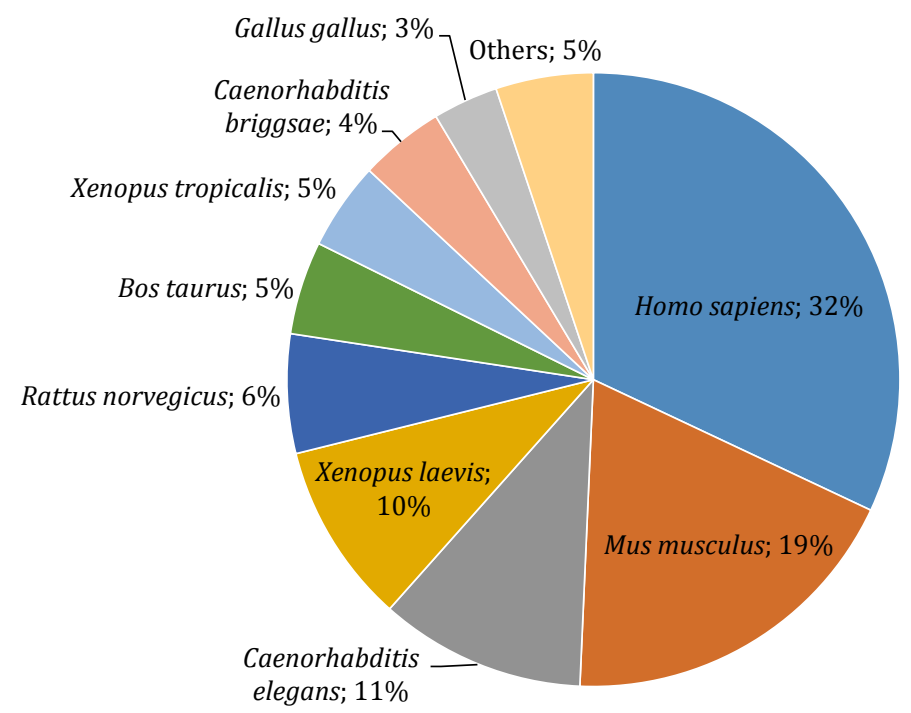

\section{Protein domain identification}

Protein domains are preserved portions of proteins with tertiary structure that can act, evolve and exist independently of the rest of the protein chain (Jacob 1977). Prediction of protein domains is an important step of transcriptome annotation since they provide insights in specific cellular functions that assist comparative genomics of domain families across species (Ochoa et al. 2011). The Pfam database is a large collection of protein families that currently contains 16,303 families (Pfam v30.0). From the predicted 45,466 protein-coding genes in the transcriptome of $O$. cruralis, we identified 23,500 that are present in the Pfam-A database, consisting of 5,686 protein domain families. We found that the most common Pfam domain in the transcriptome of $O$. cruralis is the 'Zinc finger, $\mathrm{C} 2 \mathrm{H} 2$ type' (961 hits; 4.09\%). The $\mathrm{C} 2 \mathrm{H} 2$ zinc finger proteins are very frequent in eukaryotic genomes (e.g. the human genome has 564 $\mathrm{C} 2 \mathrm{H} 2$ zinc fingers; Tadepally et al. 2008), and their functions are extraordinarily diverse, including DNA recognition, RNA packaging, transcriptional activation, regulation of apoptosis, protein folding and assembly, and lipid binding (Laity et al. 2001). Interestingly, this protein family was also reported as the most common for other amphibians, such as the green frog 
414 (Lithobates clamitans) and the Pacific tree frog (Pseudacris regilla) (Robertson \& Cornman 415 2014).

416

417

The 'WD domain, G-beta repeat' was the second most common Pfam domain in O. cruralis transcriptome ( 840 hits; $3.57 \%$ ). The $\mathrm{G}$ protein family is involved in signal transduction from outside a cell to its interior (Umbarger et al. 1992), and in frog oocytes they are important

420 regulating the maturation process (Kalinowski et al. 2003). Another essential domain for frogs is the 'Protein kinase domain' that we found as the third more abundant (643 hits; 2.74\%). This domain is supposed to play an important role in frogs in freezing tolerance during cold winters, likely inducing the transcription of antioxidant response genes (Dieni \& Storey 2014). Although freezing winters are not common within the current range of $O$. cruralis, the relative abundance of protein kinase domains could have been important in the evolutionary history of Oreobates, a genus that may have originated at high altitude in the Andes (Padial et al. 2008). It is also remarkably the high number of immunoglobulin-related domains found within the top 10 Pfam domains in the transcriptome of $O$. cruralis (1,066 hits; 4.54\%) (Table 2). Immunoglobulin domains are involved in a wide range of functions, including cell-cell recognition, cell-surface receptors, muscle structure and immune system function (Isenman et al. 1975). In frogs, as in the Yunnan firebelly toad (Bombina maxima) (Zhao et al. 2014), these domains are essential for the regulation of immune responses, allowing them to survive in harsh environmental conditions. It is possible that tropical rainforests could host a large diversity of potential pathogens imposing a positive selection on immunoglobulin-related domains in Oreobates frogs, but this hypothesis remains to be tested.

Table 2: Top 10 Pfam domains identified in the transcriptome of $O$. cruralis.

\begin{tabular}{llll}
\hline No & Pfam domain & Pfam ID & N-hits \\
\hline $\mathbf{1}$ & Zinc finger, C2H2 type & PF00096.23 & 961 \\
\hline $\mathbf{2}$ & WD domain, G-beta repeat & PF00400.29 & 840 \\
\hline $\mathbf{3}$ & Protein kinase domain & PF00069.22 & 643 \\
\hline $\mathbf{4}$ & Protein tyrosine kinase & PF07714.14 & 608 \\
\hline $\mathbf{5}$ & C2H2-type zinc finger & PF13912.3 & 593 \\
\hline $\mathbf{6}$ & C2H2-type zinc finger & PF13894.3 & 570 \\
\hline $\mathbf{7}$ & Ankyrin repeat & PF00023.27 & 553 \\
\hline $\mathbf{8}$ & Immunoglobulin I-set domain & PF07679.13 & 549 \\
\hline $\mathbf{9}$ & Immunoglobulin domain & PF00047.22 & 517 \\
\hline $\mathbf{1 0}$ & Leucine rich repeat & PF13855.3 & 482 \\
\hline
\end{tabular}


452

453

454

Figure 5: Distribution of top-10 gene ontology GO terms in the transcriptome of $O$ cruralis identified by homology with the databases via SwissProt and Pfam. Categories shown correspond to gene ontology level 2.

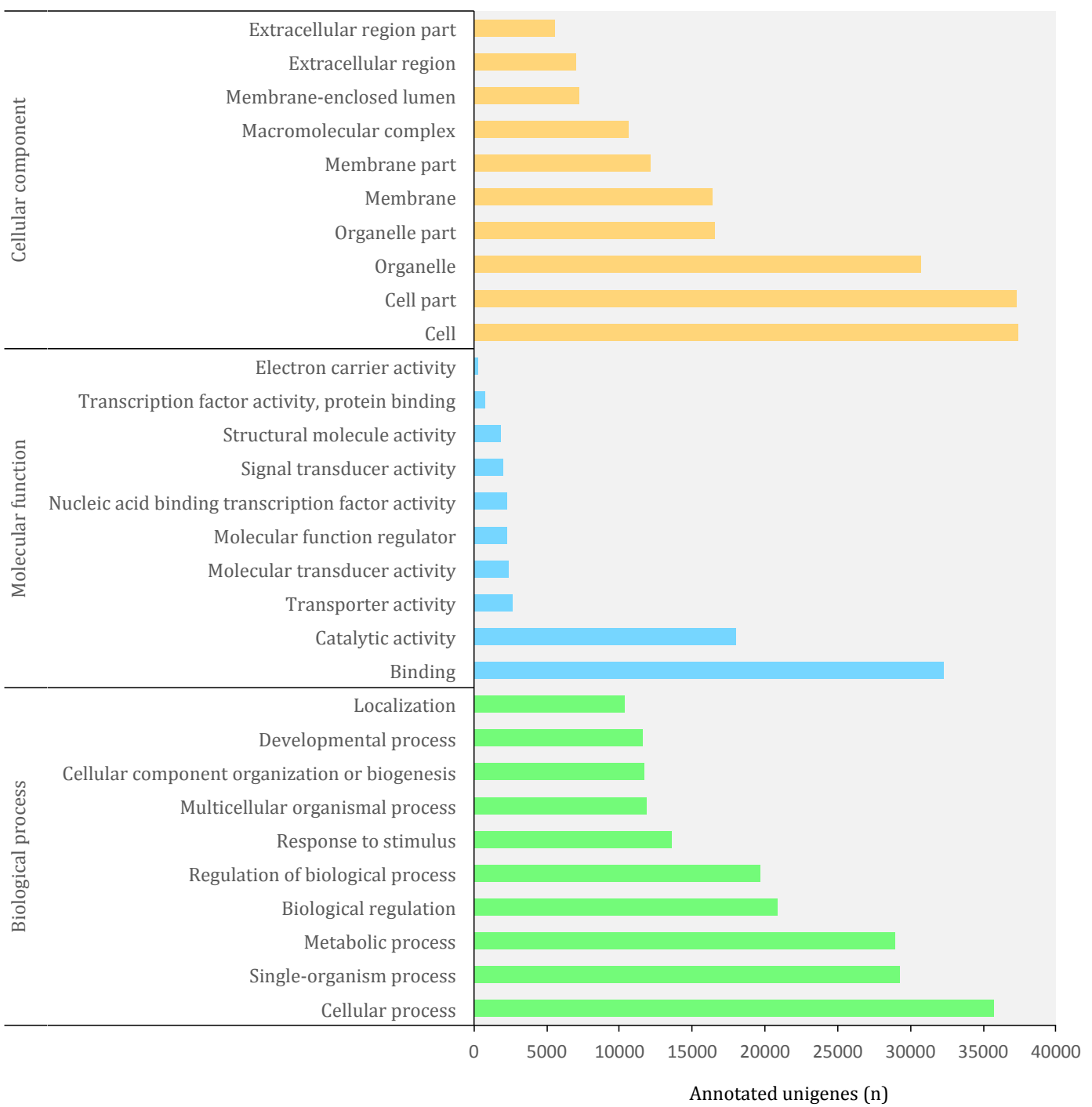

Annotated unigenes (n)

\section{Gene ontology}

The Gene Ontology (GO) (http://geneontology.org/) is a standardized functional classification system aimed to describe gene and gene product attributes across species, using a controlled vocabulary (i.e. ontology terms). The GO classification comprises three domains: cellular component, molecular function and biological process. These domains have a hierarchical structure and a GO term can belong to different levels depending on the path followed and the number of steps between the term and the root (Ashburner et al. 2000). Using the combined results of a homology search via SwissProt and Pfam, we detected a total of $3,094,863$ GO terms (19,407 unique) corresponding to 45,885 (10.85\%) unigenes in the transcriptome of $O$. cruralis. This contrasts previous studies that have reported that between 50 and $80 \%$ of the transcripts reconstructed from RNA-seq data can be annotated with GO terms 
469 (Conesa et al. 2016). However, the relatively low percentage of annotation may reflect the 470 scarcity of amphibian sequences in the GO database, and therefore the presence of undetected 471 novel transcripts. Still, the GO database produced the highest number of annotated unigenes 472 compared to other sources, such as Pfam, KEGG or EggNOG (Figure 5). The largest number of 473 GO terms corresponded to the category of "Biological Process" (49\%) followed by "Cellular 474 Component" (38\%) and "Molecular Function" (13\%). At ontology level-2, which represents the 475 second most general category in the GO database, there were 65 different GO terms (Figure 6). 476 Within the "Biological Process" category, the most frequent GO terms were "cellular process" 477 (35,730) and "single-organism process" (29,237). Within the "Molecular Function" category, 478 unigenes were mainly associated to "binding" $(32,275)$ and "catalytic activity" $(18,023)$. Within the "Cellular Component" category, unigenes were mostly associated with "cell" $(37,424)$ and "cell part" $(37,293)$. These highly abundant GO terms are likely associated to genes involved in essential cell functions and metabolism regulation, since they describe very general terms. A similar distribution of GO terms was found in a comparative transcriptome study of seven anuran species (Huang et al. 2016). We found 185 unigenes with antioxidant activity, most of them with peroxidase activity (128). This number is relatively high compared to the 63 antioxidant genes present in humans (Gelain et al. 2009) and it might be related to the high number of protein kinase domains that we recorded earlier, as well as to the habitat of $O$. cruralis. Specimens are usually encountered in tropical rainforest leaf litter, where amphibian pathogens are common (Pounds et al. 2006). Antioxidant genes have previously been reported from the skin of amphibians, contributing to resistance against microorganism infection or radiation injury (Yang et al. 2009). However, since the transcriptome of $O$. cruralis was built from tissues of intestine, liver and spleen, our results suggest that antioxidant genes in amphibians can also be expressed in different tissues besides skin. Because $O$. cruralis is mainly a lowland Amazonian rainforests frog, it would be interesting to compare this results with closely-related species living in higher altitudes (e.g. Oreobates ayacucho), where temperature is lower and microbial activity too.

\section{COG classification}

The database of Clusters of Orthologous Groups (COGs) is another common tool for functional annotation (Galperin et al. 2015). In this database, orthologous genes from 722 prokaryote genomes are grouped according to their biological function. The current version consists of 4,632 COGs classified into 26 functional categories. The EggNOG database is based on the original idea of COGs and expands it to non-supervised orthologous groups from numerous organisms, including eukaryotes and viruses (Huerta-Cepas et al. 2016). We identified a total of 37,349 (8.83\%) unigenes that are present in the EggNOG database (Figure 5). Of these, 12,993 belonged to the COG database, corresponding to 24 functional categories (Figure 7). The "general function" category $(3,166 ; 24.37 \%)$ represented the largest group, followed by "defense mechanisms" $(1,421 ; 10.94 \%)$. Our results showed that genes related to defense functions may be relatively abundant in the transcriptome of $O$. cruralis, particularly compared to the seven anurans studied by Huang et al. (2016) and also to A. mexicanum (Wu et al. 2013). In both studies, only about $2 \%$ of unigenes corresponded to defense mechanisms. Within the unigenes involved in defense mechanisms, we identified $1,163(81.84 \%)$ that are related to Cytochrome P450 enzymes (CYPs), while only 57 of those genes have been found in humans (Zanger \& Schwab 2013). CYPs are a protein superfamily in charge of metabolizing potentially toxic compounds, such as drugs or products of endogenous metabolism (Fujita et al. 2004). This large 
515 difference in the number of genes in humans and $O$. cruralis may indicate the presence of duplicates in our data, but it could also be associated with some degree of myrmecophagy (feeding on ants) in this group of frogs. Because the eating habits of Oreobates frogs have not been studied yet, protein data from strict myrmecophagous species (e.g. poison dart frogs in the family Dendrobatidae) are needed to confirm these results.

Figure 6: Distribution of Clusters of Orthologous Groups (COG) categories in the transcriptome of O cruralis.

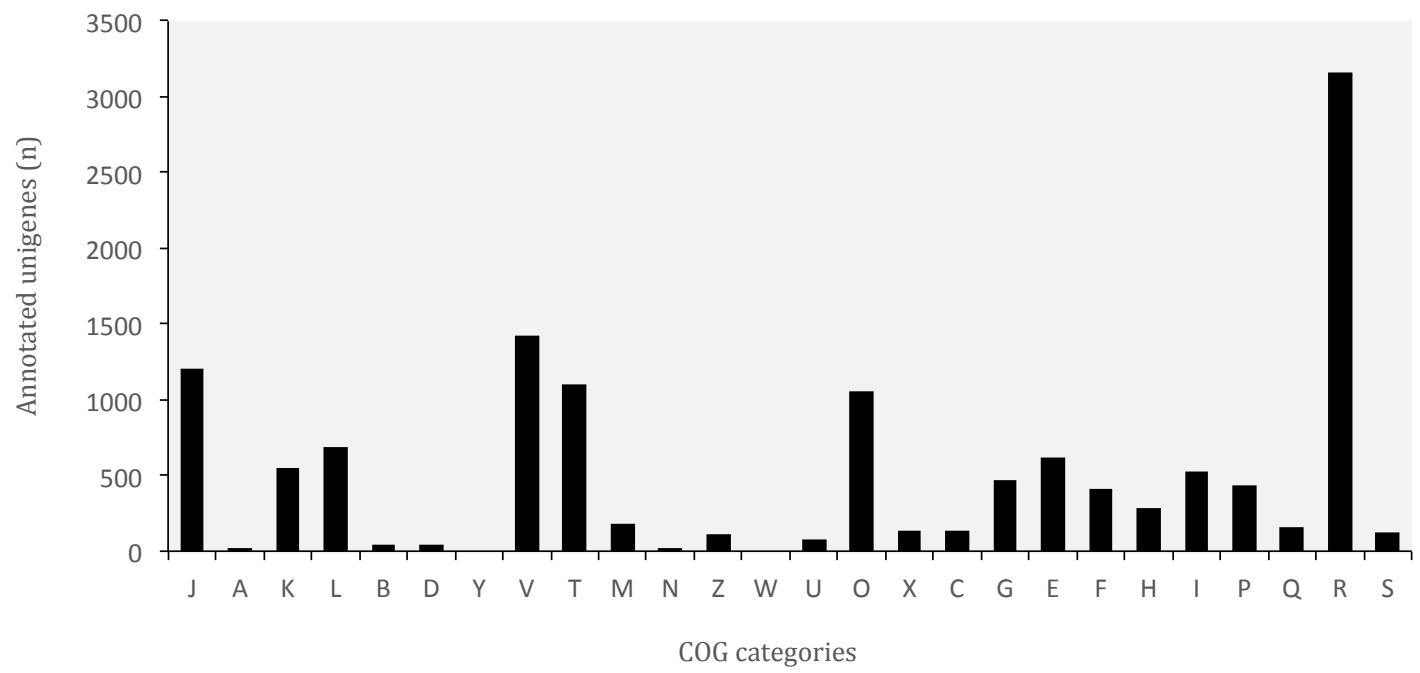

J: Translation, ribosomal structure and biogenesis. A: RNA processing and modification. K: Transcription. L: Replication, recombination and repair. B: Chromatin structure and dynamics. D: Cell cycle control, cell division, chromosome partitioning. Y: Nuclear structure. V: Defense mechanisms. T: Signal transduction mechanisms. M: Cell wall/membrane/envelope biogenesis. N: Cell motility. Z: Cytoskeleton. W: Extracellular structures. U: Intracellular trafficking, secretion, and vesicular transport. O: Posttranslational modification, protein turnover, chaperones. X: Mobilome: prophages, transposons. C: Energy production and conversion. G: Carbohydrate transport and metabolism. E: Amino acid transport and metabolism. F: Nucleotide transport and metabolism. H: Coenzyme transport and metabolism. I: Lipid transport and metabolism. P: Inorganic ion transport and metabolism. Q: Secondary metabolites biosynthesis, transport and catabolism. R: General function prediction only. S: Function unknown. 
Figure 7: Distribution of KEGG Orthology (KO) categories in the transcriptome of $O$ cruralis.

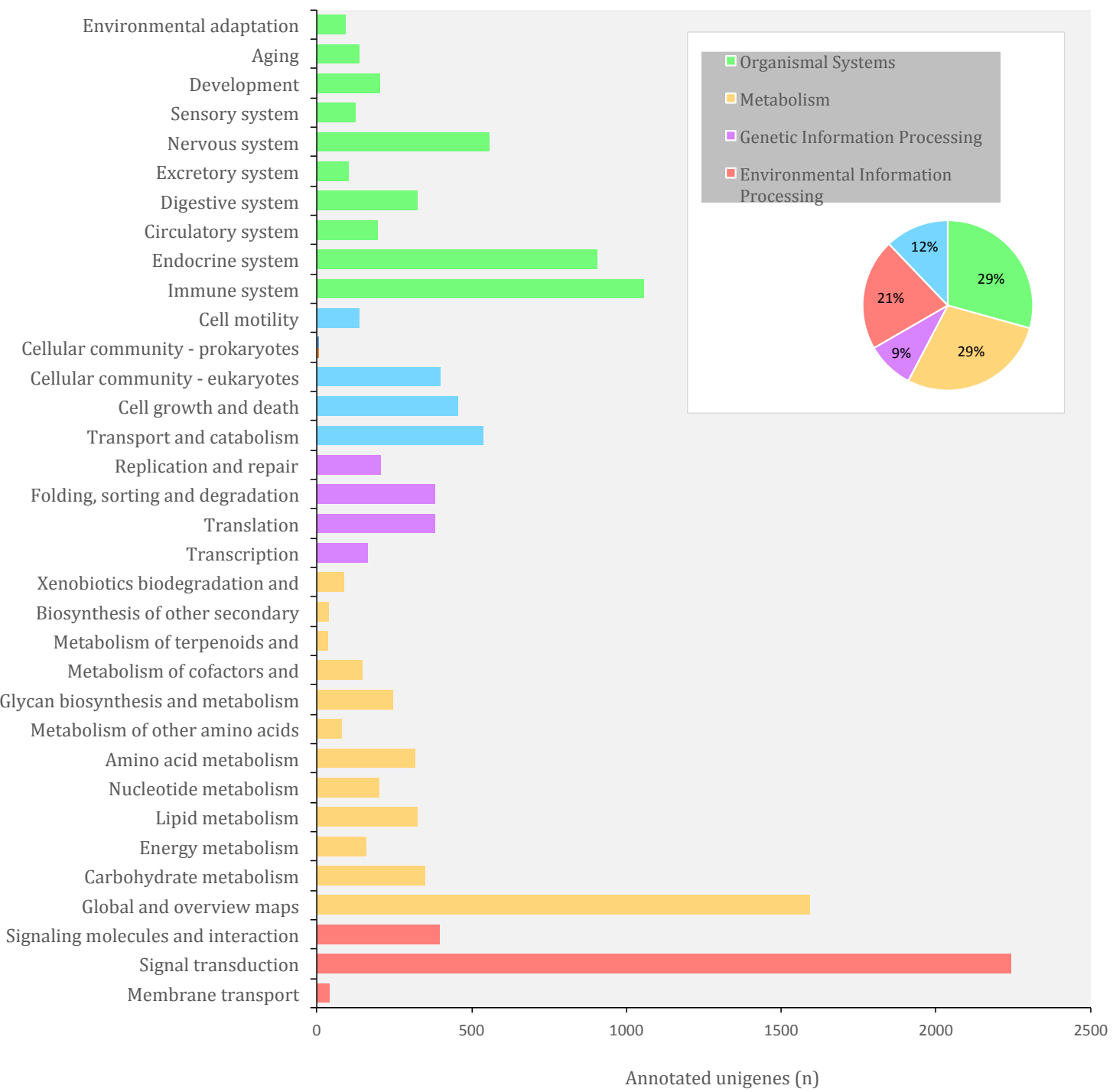

\section{KEGG pathways}

In the KEGG (Kyoto Encyclopedia of Genes and Genomes) database, genes from completely sequenced genomes are linked to higher-level systemic functions of the cell, the organism and the ecosystem (Kanehisa \& Goto 2000). Molecular-level functions are stored in the $\mathrm{KO}$ (KEGG Orthology) database, where each $\mathrm{KO}$ is defined as a functional ortholog of genes and gene products (Kanehisa et al. 2016). We identified a total of 38,120 (9.01\%) unigenes from O. cruralis in the KEGG database (Figure 5). Of these, 25,619 unigenes have orthologs in the $56429.32 \%)$, followed by metabolism $(3580 ; 28.34 \%)$, environmental information processing $(2678$; $56521.20 \%)$, cellular processes $(1535 ; 12.15 \%)$ and genetic information processing $(1135 ; 8.99 \%)$ 566 (Figure 7). We found the largest number of unigenes to be related with signal transduction 567 (2241) within the category of environmental information processing. Particularly, the PI3K-Akt 
568 signaling pathway was the most frequent $(184 ; 8.21 \%)$ among the signal transduction unigenes, 569 followed by the MAPK signaling pathway $(152 ; 6.78 \%)$. Both the PI3K-Akt and the MAPK 570 signaling pathways play a major role in the development of immune cells (Liu et al. 2007; 571 Juntilla \& Koretzky 2008). Interestingly, the immune system category was also highly enriched 572 (1057 unigenes) and within the immune category, the chemokine signaling pathway comprised 573 the highest number of unigenes $(105 ; 9.93 \%)$. Chemokine receptors associate with $\mathrm{G}$ proteins to 574 promote signaling cascades, including MAPK pathways, that cause immune responses such as 575 degranulation, a cellular process that releases antimicrobial cytotoxic molecules to destroy 576 invading microorganisms (Murdoch \& Finn 2000). This suggests that, compared to other genes, those related to the immune system are relatively abundant in the transcriptome of $O$. cruralis. We hypothesize that tropical conditions, in which high temperature and humidity are constant throughout the year, impose a crucial challenge to amphibian fitness. Although based on a single transcriptome our results lack of statistical power, this study provides a first view towards the understanding of gene evolution in Neotropical amphibians.

\section{Conclusions}

Although large genome size renders complete genome sequencing practically unfeasible in many species, such as most amphibians, transcriptome sequencing represents a cost-effective alternative to obtain a large amount of genome-wide data. This can allow the study of selection and adaptation in natural populations, but it will also lead to advances in the study of ecological and evolutionary processes beyond the limits imposed by the use of small panels of markers. In this study, we have provided and discussed a pipeline that covers the basic elements needed to build a de-novo transcriptome from RNA-seq data of non-model organisms for which sequencing and assembling a genome is not a practical option. We have successfully applied this pipeline to obtain the transcriptome profile of Oreobates cruralis, a poorly known Neotropical frog. The data obtained here has some limitations: the specimen was unsexed, and only three tissues and one life stage were represented. Thus, the results should be taken with caution in the context of sex-specific gene expression. Nevertheless, this is the first transcriptome data available for a South American amphibian, and therefore, a stepping-stone towards the study of the diversification patterns across this group of vertebrates using genomic approaches. Once a reference transcriptome is available, capture-based approaches can help to obtain homologous sequences for a large array of closely related species at a reduced cost. In this regard, this transcriptome will serve as a valuable resource for the inference of orthologous sequences in closely related species. This, for example, will allow solving phylogenomic relationships among the species of the genus Oreobates, as well as studying population differentiation, demographic history and gene evolution for the different species.

\section{Acknowledgements}

The tissue samples used for this study were provided by the frozen tissue collection of the Museo Nacional de Ciencias Naturales (MNCN-CSIC) in Madrid, Spain (MNCN/ADN collection). Sequencing was performed by the SNP\&SEQ Technology Platform in Uppsala, Sweden. The facility is part of the National Genomics Infrastructure (NGI) Sweden and Science for Life Laboratory. The SNP\&SEQ Platform is also supported by the Swedish Research Council and the Knut and Alice Wallenberg Foundation. Computations were performed on resources 
614 provided by SNIC through Uppsala Multidisciplinary Center for Advanced Computational 615 Science (UPPMAX) under Project b2015409. We thank all the members of the Conservation and 616 Evolutionary Genetics Group, as well as Dr. José Manuel Padial for constructive comments and 617 618 support in the study. We also thank Anna Olsson for laboratory support.

620

621

622

623

624

625

626

627

628

629

630

631

632

633

634

635

636

637

638

639

640

641

642

643

644

645

646

647

648

649

650

651

652

653

654

655

656

657

658

659

\section{References}

Altschul SF, Gish W, Miller W, Myers EW, Lipman DJ (1990) Basic local alignment search tool. Journal of molecular biology, 215, 403-10.

Ashburner M, Ball CA, Blake JA, Botstein D, Butler H, Cherry JM, Davis AP, Dolinski K, Dwight SS, Eppig JT, Harris MA, Hill DP, Issel-Tarver L, Kasarskis A, Lewis S, Matese JC, Richardson JE, Ringwald M, Rubin GM, Sherlock G (2000) Gene Ontology: tool for the unification of biology. Nature genetics, 25, 25-29.

Bairoch, A., \& Apweiler, R. (2000) The SWISS-PROT protein sequence database and its supplement TrEMBL in 2000. Nucleic Acids Research, 28(1), 45-48.

Bolger AM, Lohse M, Usadel B (2014) Trimmomatic: A flexible trimmer for Illumina sequence data. Bioinformatics, 30, 2114-2120.

Bryant DM, Johnson K, DiTommaso T, Tickle T, Couger MB, Payzin-Dogru D, Lee TJ, Leigh ND, Kuo TH, Davis FG, Bateman J, Bryant S, Guzikowski AR, Tsai SL, Coyne S, Ye WW, Freeman RM Jr, Peshkin L, Tabin CJ, Regev A, Haas BJ, Whited JL (2017) A TissueMapped Axolotl De Novo Transcriptome Enables Identification of Limb Regeneration Factors. Cell Reports, 18, 762-776.

Camacho-Sanchez M, Burraco P, Gomez-Mestre I, Leonard JA (2013) Preservation of RNA and DNA from mammal samples under field conditions. Molecular Ecology Resources, 13, 663-673.

Conesa A, Götz S, García-Gómez JM, Terol J, Talón M, Robles M (2005) Blast2GO: A universal tool for annotation, visualization and analysis in functional genomics research. Bioinformatics, 21, 3674-3676.

Conesa A, Madrigal P, Tarazona S, Gomez-Cabrero D, Cervera A, McPherson A, Szcześniak MW, Gaffney DJ, Elo LL, Zhang X, Mortazavi A (2016) A survey of best practices for RNA-seq data analysis. Genome Biology, 17, 13.

Destro-Bisol G, Jobling MA, Rocha J, Novembre J, Richards MB, Mulligan C, Batini C, Manni F (2010) Molecular Anthropology in the genomic era. In: Journal of Anthropological Sciences, pp. 93-112.

Dieni CA, Storey KB (2014) Protein kinase C in the wood frog, Rana sylvatica: reassessing the tissue-specific regulation of PKC isozymes during freezing. PeerJ, 2, e558.

Finn RD, Clements J, Eddy SR (2011) HMMER web server: Interactive sequence similarity searching. Nucleic Acids Research, 39, W29-W37.

Fujita Y, Ohi H, Murayama N, Saguchi K, Higuchi S (2004) Identification of multiple cytochrome P450 genes belonging to the CYP4 family in Xenopus laevis: cDNA cloning of CYP4F42 and CYP4V4. Comparative Biochemistry and Physiology Part B: Biochemistry and Molecular Biology, 138, 129-136.

Galperin MY, Makarova KS, Wolf YI, Koonin E V (2015) Expanded microbial genome coverage and improved protein family annotation in the COG database. Nucleic acids research, 43, D261-9.

Gelain DP, Dalmolin RJ, Belau VL, Moreira JC, Klamt F, Castro MA (2009) A systematic 
660

661

662

663

664

665

666

667

668

669

670

671

672

673

674

675

676

677

678

679

680

681

682

683

684

685

686

687

688

689

690

691

692

693

694

695

696

697

698

699

700

701

702

703

704

705

review of human antioxidant genes. Frontiers in bioscience (Landmark edition), 14, 445763.

Geraldes A, Pang J, Thiessen N, Cezard T, Moore R, Zhao Y, Tam A, Wang S, Friedmann M, Birol I, Jones SJ, Cronk QC, Douglas CJ (2011) SNP discovery in black cottonwood (Populus trichocarpa) by population transcriptome resequencing. Molecular Ecology Resources, 11, 81-92.

Gerchen JF, Reichert SJ, Röhr JT, Dieterich C, Kloas W, Stöck M (2016) A single transcriptome of a green toad (Bufo viridis) yields candidate genes for sex determination and differentiation and non-anonymous population genetic markers. PLOS ONE, 11, 1-14.

Giallourakis C, Henson C, Reich M, Xie X, Mootha VK (2005) Disease gene discovery through integrative genomics. Annual review of genomics and human genetics, 6, 381-406.

Grabherr MG, Haas BJ, Yassour M, Levin JZ, Thompson DA, Amit I, Adiconis X, Fan L, Raychowdhury R, Zeng Q, Chen Z, Mauceli E, Hacohen N, Gnirke A, Rhind N, di Palma F, Birren BW, Nusbaum C, Lindblad-Toh K, Friedman N, Regev A (2011) Full-length transcriptome assembly from RNA-Seq data without a reference genome. Nature biotechnology, 29, 644-52.

Gregory TR, Nicol JA, Tamm H, Kullman B, Kullman K, Leitch IJ, Murray BG, Kapraun DF, Greilhuber J, Bennett MD (2007) Eukaryotic genome size databases. Nucleic Acids Research, 35.

Haas BJ, Papanicolaou A, Yassour M, Grabherr M, Blood PD, Bowden J, Couger MB, Eccles D, Li B, Lieber M, MacManes MD, Ott M, Orvis J, Pochet N, Strozzi F, Weeks N, Westerman R, William T, Dewey CN, Henschel R, Leduc RD, Friedman N, Regev A (2013) De novo transcript sequence reconstruction from RNA-seq using the Trinity platform for reference generation and analysis. Nature Protocols, 8, 1494-1512.

Hall KW, Eisthen HL, Williams BL (2016) Proteinaceous pheromone homologs identified from the cloacal gland transcriptome of a male axolotl, Ambystoma mexicanum. PLoS ONE, 11, $1-18$.

Hellsten U, Harland RM, Gilchrist MJ, Hendrix D, Jurka J, Kapitonov V, Ovcharenko I, Putnam NH, Shu S, Taher L, Blitz IL, Blumberg B, Dichmann DS, Dubchak I, Amaya E, Detter JC, Fletcher R, Gerhard DS, Goodstein D, Graves T, Grigoriev IV, Grimwood J, Kawashima T, Lindquist E, Lucas SM, Mead PE, Mitros T, Ogino H, Ohta Y, Poliakov AV, Pollet N, Robert J, Salamov A, Sater AK, Schmutz J, Terry A, Vize PD, Warren WC, Wells D, Wills A, Wilson RK, Zimmerman LB, Zorn AM, Grainger R, Grammer T, Khokha MK, Richardson PM, Rokhsar DS (2010) The genome of the Western clawed frog Xenopus tropicalis. Science, 328, 633-6.

Huang L, Li J, Anboukaria H, Luo Z, Zhao M, Wu H (2016) Comparative transcriptome analyses of seven anurans reveal functions and adaptations of amphibian skin. Scientific Reports, 6, 24069.

Huerta-Cepas J, Szklarczyk D, Forslund K, Cook H, Heller D, Walter MC, Rattei T, Mende DR, Sunagawa S, Kuhn M, Jensen LJ, von Mering C, Bork P (2016) eggNOG 4.5: a hierarchical orthology framework with improved functional annotations for eukaryotic, prokaryotic and viral sequences. Nucleic Acids Research, 44, D286-D293.

Isenman DE, Painter RH, Dorrington KJ (1975) The structure and function of immunoglobulin domains: studies with beta-2-microglobulin on the role of the intrachain disulfide bond. Proceedings of the National Academy of Sciences of the United States of America, 72, 54852. 
706

707

708

709

710

711

712

713

714

715

716

717

718

719

720

721

722

723

724

725

726

727

728

729

730

731

732

733

734

735

736

737

738

739

740

741

742

743

744

745

746

747

748

749

750

751

Jacob F (1977) Evolution and tinkering. Science, 196, 1161-1166.

Juntilla MM, Koretzky GA (2008) Critical roles of the PI3K/Akt signaling pathway in T cell development. Immunology letters, 116, 104-10.

Kalinowski RR, Jaffe LA, Foltz KR, Giusti AF (2003) A receptor linked to a Gi-family Gprotein functions in initiating oocyte maturation in starfish but not frogs. Developmental Biology, 253, 139-149.

Kanehisa M, Furumichi M, Tanabe M, Sato Y, Morishima K (2016) KEGG: new perspectives on genomes, pathways, diseases and drugs. Nucleic Acids Research, 45, D353-D361.

Kanehisa M, Goto S (2000) Kyoto Encyclopedia of Genes and Genomes. Nucleic Acids Research, 28, 27-30.

Kanehisa M, Goto S, Sato Y, Furumichi M, Tanabe M (2012) KEGG for integration and interpretation of large-scale molecular data sets. Nucleic Acids Research, 40, D109-D114.

Köhler J, Padial JM (2016) Description and phylogenetic position of a new (singleton) species of Oreobates Jiménez De La Espada, 1872 (Anura: Craugastoridae) from the yungas of Cochabamba, Bolivia. Annals of Carnegie Museum, 84, 23-38.

Kopylova E, Noé L, Touzet H (2012) SortMeRNA: Fast and accurate filtering of ribosomal RNAs in metatranscriptomic data. Bioinformatics, 28, 3211-3217.

Kornobis E, Cabellos L, Aguilar F, Frías-López C, Rozas J, Marco J, Zardoya R (2015) TRUFA : A User-Friendly Web Server for de novo RNA-seq Analysis Using Cluster Computing. Evolutionary bioinformatics online, 11, 97-104.

De la Riva I, Köhler J, Lötters S, Reichle S (2000) Ten years of research on Bolivian amphibians: updated checklist, distribution, taxonomic problems, literature and iconography. Revista Española de Herpetología, 14, 19-164.

Laity JH, Lee BM, Wright PE (2001) Zinc finger proteins: new insights into structural and functional diversity. Current opinion in structural biology, 11, 39-46.

Lamichhaney S, Berglund J, Almén MS, Maqbool K, Grabherr M, Martinez-Barrio A, Promerová M, Rubin CJ, Wang C, Zamani N, Grant BR, Grant PR, Webster MT, Andersson L (2015) Evolution of Darwin's finches and their beaks revealed by genome sequencing. Nature, 518, 371-375.

Lamichhaney S, Han F, Berglund J, Wang C, Almén MS, Webster MT, Grant BR, Grant PR, Andersson L (2016) A beak size locus in Darwin's finches facilitates character displacement during a drought. Science, 352, 470-474.

Lamichhaney S, Martinez Barrio A, Rafati N, Sundström G, Rubin CJ, Gilbert ER, Berglund J, Wetterbom A, Laikre L, Webster MT, Grabherr M, Ryman N, Andersson L (2012) Population-scale sequencing reveals genetic differentiation due to local adaptation in Atlantic herring. Proceedings of the National Academy of Sciences, 109, 19345-50.

Lander ES, Linton LM, Birren B, Nusbaum C, Zody MC, Baldwin J, Devon K, Dewar K, Doyle M, FitzHugh W, Funke R, Gage D, Harris K, Heaford A, Howland J, Kann L, Lehoczky J, LeVine R, McEwan P, McKernan K, Meldrim J, Mesirov JP, Miranda C, Morris W, Naylor J, Raymond C, Rosetti M, Santos R, Sheridan A, Sougnez C, Stange-Thomann Y, Stojanovic N, Subramanian A, Wyman D, Rogers J, Sulston J, Ainscough R, Beck S, Bentley D, Burton J, Clee C, Carter N, Coulson A, Deadman R, Deloukas P, Dunham A, Dunham I, Durbin R, French L, Grafham D, Gregory S, Hubbard T, Humphray S, Hunt A, Jones M, Lloyd C, McMurray A, Matthews L, Mercer S, Milne S, Mullikin JC, Mungall A, Plumb R, Ross M, Shownkeen R, Sims S, Waterston RH, Wilson RK, Hillier LW, McPherson JD, Marra MA, Mardis ER, Fulton LA, Chinwalla AT, Pepin KH, Gish WR, 
752

753

754

755

756

757

758

759

760

761

762

763

764

765

766

767

768

769

770

771

772

773

774

775

776

777

778

779

780

781

782

783

784

785

786

787

788

789

790

791

792

793

794

795

796

797

Chissoe SL, Wendl MC, Delehaunty KD, Miner TL, Delehaunty A, Kramer JB, Cook LL, Fulton RS, Johnson DL, Minx PJ, Clifton SW, Hawkins T, Branscomb E, Predki P, Richardson P, Wenning S, Slezak T, Doggett N, Cheng JF, Olsen A, Lucas S, Elkin C, Uberbacher E, Frazier M, Gibbs RA, Muzny DM, Scherer SE, Bouck JB, Sodergren EJ, Worley KC, Rives CM, Gorrell JH, Metzker ML, Naylor SL, Kucherlapati RS, Nelson DL, Weinstock GM, Sakaki Y, Fujiyama A, Hattori M, Yada T, Toyoda A, Itoh T, Kawagoe C, Watanabe H, Totoki Y, Taylor T, Weissenbach J, Heilig R, Saurin W, Artiguenave F, Brottier P, Bruls T, Pelletier E, Robert C, Wincker P, Smith DR, Doucette-Stamm L, Rubenfield M, Weinstock K, Lee HM, Dubois J, Rosenthal A, Platzer M, Nyakatura G, Taudien S, Rump A, Yang H, Yu J, Wang J, Huang G, Gu J, Hood L, Rowen L, Madan A, Qin S, Davis RW, Federspiel NA, Abola AP, Proctor MJ, Myers RM, Schmutz J, Dickson M, Grimwood J, Cox DR, Olson MV, Kaul R, Raymond C, Shimizu N, Kawasaki K, Minoshima S, Evans GA, Athanasiou M, Schultz R, Roe BA, Chen F, Pan H, Ramser J, Lehrach H, Reinhardt R, McCombie WR, de la Bastide M, Dedhia N, Blöcker H, Hornischer K, Nordsiek G, Agarwala R, Aravind L, Bailey JA, Bateman A, Batzoglou S, Birney E, Bork P, Brown DG, Burge CB, Cerutti L, Chen HC, Church D, Clamp M, Copley RR, Doerks T, Eddy SR, Eichler EE, Furey TS, Galagan J, Gilbert JG, Harmon C, Hayashizaki Y, Haussler D, Hermjakob H, Hokamp K, Jang W, Johnson LS, Jones TA, Kasif S, Kaspryzk A, Kennedy S, Kent WJ, Kitts P, Koonin EV, Korf I, Kulp D, Lancet D, Lowe TM, McLysaght A, Mikkelsen T, Moran JV, Mulder N, Pollara VJ, Ponting CP, Schuler G, Schultz J, Slater G, Smit AF, Stupka E, Szustakowki J, Thierry-Mieg D, Thierry-Mieg J, Wagner L, Wallis J, Wheeler R, Williams A, Wolf YI, Wolfe KH, Yang SP, Yeh RF, Collins F, Guyer MS, Peterson J, Felsenfeld A, Wetterstrand KA, Patrinos A, Morgan MJ, de Jong P, Catanese JJ, Osoegawa K, Shizuya H, Choi S, Chen YJ, Szustakowki J; International Human Genome Sequencing Consortium (2001) Initial sequencing and analysis of the human genome. Nature, 409, 860-921.

Langmead B, Trapnell C, Pop M, Salzberg SL (2009) Ultrafast and memory-efficient alignment of short DNA sequences to the human genome. Genome biology, 10, R25.

Li B, Fillmore N, Bai Y, Collins M, Thomson JA, Stewart R, Dewey CN (2014) Evaluation of de novo transcriptome assemblies from RNA-Seq data. Genome Biology, 15, 553.

Liu Y, Shepherd EG, Nelin LD (2007) MAPK phosphatases — regulating the immune response. Nature Reviews Immunology, 7, 202-212.

Martin J a., Wang Z (2011) Next-generation transcriptome assembly. Nature Reviews Genetics, 12, 671-682.

McBride CM, Bowen D, Brody LC, Condit CM, Croyle RT, Gwinn M, Khoury MJ, Koehly LM, Korf BR, Marteau TM, McLeroy K, Patrick K, Valente TW (2010) Future Health Applications of Genomics. Priorities for Communication, Behavioral, and Social Sciences Research. American Journal of Preventive Medicine, 38, 556-565.

Mcmahon BJ, Teeling EC, Höglund J (2014) How and why should we implement genomics into conservation? Evolutionary Applications, 7, 999-1007.

Mukherjee S, Stamatis D, Bertsch J, Ovchinnikova G, Verezemska O, Isbandi M, Thomas AD, Ali R, Sharma K, Kyrpides NC, Reddy TB (2017) Genomes OnLine Database (GOLD) v.6: data updates and feature enhancements. Nucleic acids research, 45, D446-D456.

Murdoch C, Finn A (2000) Chemokine receptors and their role in inflammation and infectious diseases. Blood, 95, 3032-43.

Ochoa A, Llinás M, Singh M (2011) Using context to improve protein domain identification. 
798

799

800

801

802

803

804

805

806

807

808

809

810

811

812

813

814

815

816

817

818

819

820

821

822

823

824

825

826

827

828

829

830

831

832

833

834

835

836

837

838

839

840

841

842

843

BMC Bioinformatics, 12, 90.

Padial JM, Chaparro JC, De la Riva I (2008) Systematics of Oreobates and the Eleutherodactylus discoidalis species group (Amphibia, Anura), based on two mitochondrial DNA genes and external morphology. Zoological Journal of the Linnean Society, 152, 737-773.

Pounds JA, Bustamante MR, Coloma L, Consuegra JA, Fogden MP, Foster PN, La Marca E, Masters KL, Merino-Viteri A, Puschendorf R, Ron SR, Sánchez-Azofeifa GA, Still CJ, Young BE (2006) Widespread amphibian extinctions from epidemic disease driven by global warming. Nature, 439, 161-7.

Powell S, Szklarczyk D, Trachana K, Roth A, Kuhn M, Muller J, Arnold R, Rattei T, Letunic I, Doerks T, Jensen LJ, von Mering C, Bork P (2012) eggNOG v3.0: Orthologous groups covering 1133 organisms at 41 different taxonomic ranges. Nucleic Acids Research, 40, D284-9.

Price SJ, Garner TWJ, Balloux F, Ruis C, Paszkiewicz KH, Moore K, Griffiths AG (2015) A de novo assembly of the common frog (Rana temporaria) transcriptome and comparison of transcription following exposure to Ranavirus and Batrachochytrium dendrobatidis. PLoS $O N E, \mathbf{1 0}, 1-23$.

Reuter JA, Spacek D V., Snyder MP (2015) High-Throughput Sequencing Technologies. Molecular Cell, 58, 586-597.

Robertson LS, Cornman RS (2014) Transcriptome resources for the frogs Lithobates clamitans and Pseudacris regilla, emphasizing antimicrobial peptides and conserved loci for phylogenetics. Molecular Ecology Resources, 14, 178-183.

Schuster SC (2008) Next-generation sequencing transforms today's biology. Nature Methods, $\mathbf{5}$, $16-18$.

Session AM, Uno Y, Kwon T, Chapman JA, Toyoda A, Takahashi S, Fukui A, Hikosaka A, Suzuki A, Kondo M, van Heeringen SJ, Quigley I, Heinz S, Ogino H, Ochi H, Hellsten U, Lyons JB, Simakov O, Putnam N, Stites J, Kuroki Y, Tanaka T, Michiue T, Watanabe M, Bogdanovic O, Lister R, Georgiou G, Paranjpe SS, van Kruijsbergen I, Shu S, Carlson J, Kinoshita T, Ohta Y, Mawaribuchi S, Jenkins J, Grimwood J, Schmutz J, Mitros T, Mozaffari SV, Suzuki Y, Haramoto Y, Yamamoto TS, Takagi C, Heald R, Miller K, Haudenschild C, Kitzman J, Nakayama T, Izutsu Y, Robert J, Fortriede J, Burns K, Lotay V, Karimi K, Yasuoka Y, Dichmann DS, Flajnik MF, Houston DW, Shendure J, DuPasquier L, Vize PD, Zorn AM, Ito M, Marcotte EM, Wallingford JB, Ito Y, Asashima M, Ueno N, Matsuda Y, Veenstra GJ, Fujiyama A, Harland RM, Taira M, Rokhsar DS (2016) Genome evolution in the allotetraploid frog Xenopus laevis. Nature, 538, 1-15.

Simao FA, Waterhouse RM, Ioannidis P, Kriventseva E V., Zdobnov EM (2015) BUSCO: Assessing genome assembly and annotation completeness with single-copy orthologs. Bioinformatics, 31, 3210-3212.

Simpson JT (2014) Exploring genome characteristics and sequence quality without a reference. Bioinformatics, 30, 1228-1235.

Sun Y-B, Xiong Z-J, Xiang X-Y, Liu SP, Zhou WW, Tu XL, Zhong L, Wang L, Wu DD, Zhang BL, Zhu CL, Yang MM, Chen HM, Li F, Zhou L, Feng SH, Huang C, Zhang GJ, Irwin D, Hillis DM, Murphy RW, Yang HM, Che J, Wang J, Zhang YP (2015) Whole-genome sequence of the Tibetan frog Nanorana parkeri and the comparative evolution of tetrapod genomes. Proceedings of the National Academy of Sciences of the United States of America, 112, E1257-62.

Tadepally HD, Burger G, Aubry M (2008) Evolution of C2H2-zinc finger genes and subfamilies

Peer] reviewing PDF | (2017:04:17690:2:0:NEW 26 Jul 2017) 
844 in mammals: Species-specific duplication and loss of clusters, genes and effector domains. $845 \quad$ BMC Evolutionary Biology, 8, 176.

846

847

848

849

850

851

852

853

854

855

856

857

858

859

860

861

862

863

864

865

866

867

868

869

Umbarger KO, Yamazaki M, Hutson LD, Hayashi F, Yamazaki A (1992) Heterogeneity of the retinal G-protein transducin from frog rod photoreceptors: Biochemical identification and characterization of new subunits. Journal of Biological Chemistry, 267, 19494-19502.

Wang Z, Gerstein M, Snyder M (2009) RNA-Seq: a revolutionary tool for transcriptomics. Nature reviews. Genetics, 10, 57-63.

Wang W, Wang J, You F, Ma L, Yang X, Gao J, He Y, Qi J, Yu H, Wang Z, Wang X, Wu Z, Zhang Q (2014) Detection of alternative splice and gene duplication by RNA sequencing in Japanese flounder, Paralichthys olivaceus. G3 (Bethesda, Md.), 4, 2419-24.

De Wit P, Pespeni MH, Palumbi SR (2015) SNP genotyping and population genomics from expressed sequences - Current advances and future possibilities. Molecular Ecology, 24, $2310-2323$.

Wolfe KH (2006) Comparative genomics and genome evolution in yeasts. Philosophical transactions of the Royal Society of London. Series B, Biological sciences, 361, 403-412.

Wu C-H, Tsai M-H, Ho C-C, Chen C-Y, Lee H-S (2013) De novo transcriptome sequencing of axolotl blastema for identification of differentially expressed genes during limb regeneration. BMC genomics, 14, 434.

Yang H, Wang X, Liu X, Wu J, Liu C, Gong W, Zhao Z, Hong J, Lin D, Wang Y, Lai R (2009) Antioxidant peptidomics reveals novel skin antioxidant system. Molecular \& cellular proteomics : $M C P, \mathbf{8}, 571-83$.

Zanger UM, Schwab M (2013) Cytochrome P450 enzymes in drug metabolism: Regulation of gene expression, enzyme activities, and impact of genetic variation. Pharmacology \& Therapeutics, 138, 103-141.

Zhao F, Yan C, Wang X, Yang Y, Wang G, Lee W, Xiang Y, Zhang Y (2014) Comprehensive transcriptome profiling and functional analysis of the frog (Bombina maxima) immune

870 system. DNA Research, 21, 1-13. 